\title{
Prospective cross-sectional multicenter study on domiciliary noninvasive ventilation in stable hypercapnic COPD patients
}

This article was published in the following Dove Press journal: International Journal of COPD

\author{
Esra Ertan Yazar' \\ Tevfik Özlü \\ Muzaffer Sarıaydın ${ }^{3}$ \\ Mahșuk Taylan ${ }^{4}$ \\ Aydanur Ekici ${ }^{5}$ \\ Derya Aydın6 \\ İbrahim Güven Coșgun ${ }^{7}$ \\ Nagihan Durmuș Koçak ${ }^{8}$ \\ On behalf of the COHOV \\ Study Group \\ 'Department of Pulmonology, Yedikule \\ Chest Disease and Thoracic Surgery \\ Training and Research Hospital, \\ Istanbul, Turkey; ${ }^{2}$ Department of \\ Pulmonology, School of Medicine, \\ Karadeniz Technical University, \\ Trabzon, Turkey; ${ }^{3}$ Department of \\ Pulmonology, School of Medicine, \\ Afyon Kocatepe University, Afyon, \\ Turkey; ${ }^{4}$ Department of Pulmonology, \\ School of Medicine, Dicle University, \\ Diyarbakır, Turkey; ${ }^{5}$ Department of \\ Pulmonology, School of Medicine, \\ Kırıkkale University, Kırıkkale, Turkey; \\ ${ }^{6}$ Department of Pulmonology, Balıkesir \\ Chest Disease Government Hospital, \\ Balıkesir, Turkey; ${ }^{7}$ Department \\ of Pulmonology, Afyonkarahisar \\ Government Hospital, Afyonkarahisar, \\ Turkey; ${ }^{8}$ Department of Pulmonology, \\ Sureyyapasa Chest Disease and \\ Thoracic Surgery Training and \\ Research Hospital, Istanbul, Turkey
}

Correspondence: Esra Ertan Yazar Yedikule Chest Disease and Thoracic Surgery Training and Research Hospital, 34100 Zeytinburnu, Istanbul, Turkey Email esraertan76@yahoo.com
Background: Domiciliary noninvasive ventilation (NIV) use in stable hypercarbic COPD is becoming increasingly widespread. However, treatment compliance criteria and factors related to compliance remain to be defined.

Methods: This research was designed as a prospective, cross-sectional, multicenter real-life study. Chronic hypercapnic COPD patients who were using domiciliary NIV for at least 1 year and being followed up in 19 centers across Turkey were included in the study. The patients who used NIV regularly, night or daytime and $\geq 5$ hours/d, were classified as "high-compliance group," and patients who used NIV irregularly and $<5$ hours/d as "low-compliance group."

Results: Two hundred and sixty-six patients with a mean age of $64.5 \pm 10.3$ years were enrolled, of whom $75.2 \%$ were males. They were using domiciliary NIV for $2.8 \pm 2$ years. Spontaneous time mode $(p<0.001)$ and night use $(p<0.001)$ were more frequent in the high-compliance group $(\mathrm{n}=163)$. Also, mean inspiratory positive airway pressure values of the high-compliance group were significantly higher than the low-compliance group $(\mathrm{n}=103 ; p<0.001)$. Cardiac failure ( $p=0.049$ ) and obesity ( $p=0.01)$ were significantly more frequent in the high-compliance group. There were no difference between 2 groups regarding hospitalization, emergency department and intensive care unit admissions within the last year, as well as modified Medical Research Council dyspnea and COPD Assessment Test scores. With regard to NIV-related side effects, only conjunctivitis was observed more frequently in the high-compliance group $(p=0.002)$.

Conclusion: Determination of the patients who have better compliance to domiciliary NIV in COPD may increase the success and effectiveness of treatment. This highly comprehensive study on this topic possesses importance as it suggests that patient and ventilator characteristics may be related to treatment compliance.

Keywords: COPD, noninvasive ventilation, compliance

\section{Introduction}

Chronic obstructive pulmonary disease (COPD) is an increasing and important cause of morbidity and mortality worldwide. Among the diseases leading to death, COPD was ranked as 4th in 2015 and is expected to rise to the $3 \mathrm{rd}$ rank by $2020 .{ }^{1}$ In particular, chronic hypercapnic respiratory failure is conversely associated with overall prognosis in COPD, and also, if a patient developed hypercapnia once, 2-year mortality rate increases to approximately $30 \%-40 \% .^{2}$ In chronic hypercarbic COPD patients, long-term noninvasive ventilation (NIV) use is becoming increasingly widespread. However, the meta-analysis and clinical guidelines do not recommend domiciliary NIV except in selected patients. 3,4 
In stable COPD, long-term NIV use has been demonstrated to provide clinical and functional benefit via several mechanisms. During sleep, it may improve nocturnal hypoventilation and reduce daytime hypercapnia, thus leading to restoration of chemosensitivity and changes in ventilatory pattern. It has been demonstrated to reduce chronic muscle weakness, improve inspiratory muscle functions, and thereby, reduce hyperinflation. Also, it has been reported to improve duration and effectiveness of sleep. ${ }^{5,6}$

In terms of domiciliary NIV rates in COPD, our country is in the 2nd rank among European Respiratory Society (ERS)member European countries after Germany. In our country, due to population density and high COPD prevalence, hospitals in large cities cannot meet the increasing need of hospitalization of these patients. Therefore, domiciliary NIV is more frequently prescribed in COPD patients who were hospitalized due to acute hypercarbic respiratory failure to shorten the hospitalization period or to reduce the rates of readmission. Ventilator devices for the patients are provided by our government according to the consensus criteria. ${ }^{8}$

When we searched the literature, we could not find a comprehensive study investigating compliance to domiciliary NIV. In this study, we aimed to explore treatment compliance rates and conditions possibly related to compliance to domiciliary NIV in chronic hypercapnic COPD patients. Also, we evaluated the relationship between domiciliary NIV compliance and symptom scores, hospitalization, and emergency department and intensive care unit (ICU) admissions within the last year.

Our hypothesis was that the symptom scoring and emergency department and hospital admission would be better in the high-compliance group when compared with the low-compliance group.

\section{Methods}

This study was designed as a prospective, cross-sectional multicenter real-life trial between April 2015 and June 2016. Nineteen centers from our country participated in this study. Inclusion criteria were as follows: stable hypercarbic COPD patients using domiciliary NIV for at least 1 year, age $\geq 40$ years, and $\geq 10$ pack-year smoking history. Patients who did not have definitive diagnosis of COPD, had COPD exacerbation within the past 6 weeks prior to enrollment, were using NIV for non-COPD conditions, and did not meet aforementioned criteria were excluded from the study. Demographic and clinical characteristics were obtained by face-to-face interviews with the patients and their relatives. All diseases included in the Charlson Comorbidity Index were questioned and recorded for each patient. ${ }^{9}$ The number of hospitalizations and emergency department and ICU admissions within the last year were recorded retrospectively based on patients' self-report and hospital records. Dyspnea was assessed based on the modified Medical Research Council's (mMRC) dyspnea scale ${ }^{10}$ and the disease control status was measured by the COPD Assessment Test (CAT) for each patient. ${ }^{11}$ Pulmonary function test (PFT) and arterial blood gas (ABG) were measured if the patients' tests were not performed within the last 6 months and the results were recorded. During the interview, detailed information was obtained from each patient regarding the side effects of NIV therapy and ventilator usage features. Daily period of use in some of the patients was recorded by a readout of the ventilator's built-in software. For these patients $(n=115)$, statistically high correlation between the card readout and self-report was detected. Therefore, for the patients without available ventilator's built-in software data, periods of NIV use were recorded based on the common statement of the patients and their relatives. Patients who use NIV everyday regularly, night or daytime and $\geq 5$ hours/d, were classified as "high-compliance group," and patients who used NIV irregularly and $<5$ hours/d were the "low-compliance group." The groups were compared in terms of demographic, clinical, and laboratory characteristics, NIV-related side effects, ventilator type and setting, and also rates of hospitalization and emergency department and ICU admissions within the last year. The study was approved by the ethics committee of Karadeniz Technical University, School of Medicine, with the ethics committee number 24237859-242. A written informed consent was taken from each patient before the study.

\section{Statistical analysis}

Statistical analysis was performed using the IBM SPSS version 23 software (IBM Corporation, Armonk, NY, USA). Descriptive data were expressed as count and percentage for categorical variables and as mean and SD for continuous variables. Independent $t$-test was used to analyze the significant differences between the categorical variables having 2 groups. The $\chi^{2}$ test was used to analyze the correlation between the 2 categorical variables, while the Pearson correlation coefficients were used to analyze the correlation between the 2 numerical variables. $p$-value of $<0.05$ was considered statistically significant.

\section{Results}

Two hundred and sixty-six stable chronic hypercapnic COPD patients with a mean age of $64.5 \pm 10.3$ years were enrolled, 
of whom 75.2\% ( $n=200)$ were males. Patients were being followed up for COPD for a mean of $8.5 \pm 5$ years and were using domiciliary NIV for $2.8 \pm 2$ years. All patients had a history of smoking of at least $10 \mathrm{pack} / \mathrm{yr}$, and $20.7 \%$ were current smokers. About $59.8 \%$ of the patients had comorbidities, and the most common accompanying 3 comorbidities were cardiac failure, diabetes mellitus, and cerebrovascular diseases, respectively. Obstructive sleep apnea (OSA) previously diagnosed by polysomnography was an accompanying comorbidity in $12.4 \%$ of the patients, and obesity (body mass index [BMI] over $30 \mathrm{~kg} / \mathrm{m}^{2}$ ) was seen in $20.7 \%$ of the patients. About $89.4 \%$ of the patients were using domiciliary long-term oxygen therapy (LTOT). Patients' mean forced expiratory volume in 1 second $\left(\mathrm{FEV}_{1}\right)$ was $0.96 \pm 0.5 \mathrm{~L}, 34.5 \%$ of the expected value, and forced vital capacity (FVC) was $1.62 \pm 1 \mathrm{~L}, 47.2 \%$ of the expected value; the $\mathrm{FEV}_{1} / \mathrm{FVC}$ ratio had a mean of $54 \%$. Clinical and laboratory characteristics of the patients are given in Table 1. Ventilator type and setting: Of the patients, $50.4 \%$ were using the device in spontaneous time (ST) mode, $49.6 \%$ in spontaneous (S) mode. $92.5 \%$ of the patients were using noninvasive positive pressure ventilation (NPPV) via oronasal mask and 7.5\% via nasal mask. Mean inspiratory positive airway pressure (IPAP) used by patients was $18 \pm 5.5 \mathrm{cmH}_{2} \mathrm{O}$, and mean expiratory positive airway pressure was $5.8 \pm 1.3 \mathrm{cmH}_{2} \mathrm{O}$. Of the patients, $40.2 \%$ were using the ventilator at daytime and $59.8 \%$ at night; $67.7 \%$ of the ventilators had a humidification system. About $88.7 \%$ of the patients were informed about the ventilator

Table I Clinical and laboratory characteristics of the patients

\begin{tabular}{|c|c|c|}
\hline $\begin{array}{l}\text { The number of } \\
\text { patients: } 266\end{array}$ & Mean & SD \\
\hline Age (years) & 64.5 & 10.3 \\
\hline BMI $\left(\mathrm{kg} / \mathrm{m}^{2}\right)$ & 28.5 & 7.7 \\
\hline Smoking (pack/yr) & 45.5 & 25.7 \\
\hline $\mathrm{FEV}_{1}(\%)$ & 34.5 & 14.3 \\
\hline $\mathrm{FEV}_{1} / \mathrm{FVC}(\%)$ & 53.9 & 10.1 \\
\hline $\mathrm{pH}$ & 7.41 & 0.04 \\
\hline $\mathrm{PaCO}_{2}(\mathrm{mmHg})$ & 50.97 & 7.3 \\
\hline $\mathrm{PaO}_{2}(\mathrm{mmHg})$ & 73.8 & 25.2 \\
\hline $\mathrm{SaO}_{2}(\%)$ & 92.2 & 5.2 \\
\hline Compliance of NIV (hours/d) & 6.3 & 3 \\
\hline IPAP $\left(\mathrm{cmH}_{2} \mathrm{O}\right)$ & 18.1 & 5.5 \\
\hline $\operatorname{EPAP}\left(\mathrm{cmH}_{2} \mathrm{O}\right)$ & 5.8 & 1.3 \\
\hline CAT score & 24.3 & 8 \\
\hline mMRC score & 3.9 & I.I \\
\hline
\end{tabular}

Abbreviations: $\mathrm{BMI}$, body mass index; $\mathrm{FEV}_{1}$, forced expiratory volume in I second; FVC, forced vital capacity; $\mathrm{PaO}_{2}$, partial arterial oxygen pressure; $\mathrm{PaCO}_{2}$, partial arterial carbon dioxide pressure; $\mathrm{SaO}_{2}$, oxygen saturation; $\mathrm{NIV}$, noninvasive ventilation; IPAP, inspiratory positive airway pressure; EPAP, expiratory positive airway pressure; CAT, COPD Assessment Test; mMRC, modified Medical Research Council.
Table 2 Distribution of the side effects related to NIV

\begin{tabular}{lll}
\hline Side effects & Number (n) & $\%$ \\
\hline Headache & 98 & 36.8 \\
Sleep disruption & 81 & 30.5 \\
Feeling of suffocation & 54 & 20.3 \\
Nasal skin lesion & 41 & 15.4 \\
Conjunctivitis & 38 & 14.3 \\
Extremely high air pressure & 37 & 13.9 \\
Overall side effects & 159 & 59.8 \\
\hline
\end{tabular}

Abbreviation: NIV, noninvasive ventilation.

use and only $38.7 \%$ returned for follow-up visit by the ventilator prescribing physician. The most common 3 side effects related to NPPV were headache, sleep disruption, and feeling of suffocation. All side effects and their frequencies are given in Table 2.

\section{Comparison of the groups}

BMI was significantly higher $\left(29.5 \pm 8\right.$ vs $\left.27 \pm 7 \mathrm{~kg} / \mathrm{m}^{2} ; p=0.01\right)$ and the proportion of female gender was higher (29\% vs $18 \% ; p=0.056$ ) but not statistically significant in the highcompliance group $(n=163)$ compared to the low-compliance group ( $n=103)$. There was no difference between the groups in terms of other demographic characteristics (age, educational level, smoking status, and having a roommate). There was no difference with regard to patients' PFTs (FVC, FEV ${ }_{1}$, $\mathrm{FEV}_{1} / \mathrm{FVC}$ ) and $\mathrm{ABG}$ values (partial arterial oxygen pressure, partial arterial carbon dioxide pressure $\left[\mathrm{PaCO}_{2}\right]$, oxygen saturation, $\mathrm{pH}$ ) either.

With regard to comorbidities, heart failure was more in the high-compliance group ( $p=0.049$ ), and while the number of patients with dementia $(n=4)$ was less all of them were in the low-compliance group ( $p=0.02)$. In the high-compliance group, obesity was more frequent $(p=0.01)$ and OSA was proportionally more frequent $(15.3 \%$ vs $7.8 \%)$, but the difference was not statistically significant ( $p=0.07)$.

When the groups were compared in terms of NIV type and setting, ST mode $(p<0.001)$ and night use $(p<0.001)$ was more frequent in the high-compliance group. Also, mean IPAP values of the high-compliance group were significantly higher than the low-compliance group $(p<0.001)$. There was no difference between the 2 groups in terms of other ventilator usage features (Table 3 ). With regard to NIV-related side effects, only conjunctivitis was observed more frequently in the high-compliance group ( $p=0.002)$, and there was no difference in terms of other side effects.

There was no difference between the high- and lowcompliance groups in terms of hospitalization and emergency department and ICU admissions within the last year and also 
Table 3 Comparison of the groups with respect to NIV use, type, and setting

\begin{tabular}{|c|c|c|c|c|c|c|c|}
\hline $\begin{array}{l}\text { The NIV use, type } \\
\text { and setting }\end{array}$ & & & $\begin{array}{l}\text { High-compliance } \\
\text { group }\end{array}$ & $\begin{array}{l}\text { Low-compliance } \\
\text { group }\end{array}$ & Total & $\chi^{2}$ & $p$-value \\
\hline \multirow[t]{4}{*}{ Predominant period of use } & Daytime & $\mathrm{N}$ & 44 & 62 & 106 & & \\
\hline & & $\%$ & 27.0 & 61.4 & 40.2 & 30.695 & $0.000^{a}$ \\
\hline & Night & $\mathrm{N}$ & 119 & 39 & 158 & & \\
\hline & & $\%$ & 73.0 & 38.6 & 59.8 & & \\
\hline \multirow[t]{4}{*}{ Mode } & ST mode & $\mathrm{N}$ & 99 & 35 & 134 & & \\
\hline & & $\%$ & 60.7 & 34.0 & 50.4 & 18.074 & $0.000^{a}$ \\
\hline & S mode & $\mathrm{N}$ & 64 & 68 & 132 & & \\
\hline & & $\%$ & 39.3 & 66.0 & 49.6 & & \\
\hline \multirow[t]{4}{*}{ Humidification system } & Yes & $\mathrm{N}$ & 114 & 66 & 180 & & \\
\hline & & $\%$ & 69.9 & 64.1 & 67.7 & 0.991 & 0.319 \\
\hline & No & $\mathrm{N}$ & 49 & 37 & 86 & & \\
\hline & & $\%$ & 30.1 & 35.9 & 32.3 & & \\
\hline \multirow[t]{4}{*}{ Type of mask } & Nasal & $\mathrm{N}$ & 10 & 10 & 20 & & \\
\hline & & $\%$ & 6.1 & 9.7 & 7.5 & 1.159 & 0.282 \\
\hline & Oronasal & $\mathrm{N}$ & 153 & 93 & 246 & & \\
\hline & & $\%$ & 93.9 & 90.3 & 92.5 & & \\
\hline \multirow[t]{2}{*}{ IPAP $\left(\mathrm{cmH}_{2} \mathrm{O}\right)$} & High-com & & 163 & 18.97 & 5.79 & 3.531 & $0.000^{a}$ \\
\hline & Low-com & & 103 & 16.70 & 4.63 & & \\
\hline \multirow[t]{2}{*}{$\operatorname{EPAP}\left(\mathrm{cmH}_{2} \mathrm{O}\right)$} & High-com & & 163 & 5.8 & 1.39 & 0.421 & 0.674 \\
\hline & Low-com & & 102 & 5.74 & I.I & & \\
\hline \multirow[t]{4}{*}{ Daytime headache } & Yes & $\mathrm{N}$ & 85 & 47 & 132 & & \\
\hline & & $\%$ & 52.1 & 45.6 & 49.6 & 1.072 & 0.300 \\
\hline & No & $\mathrm{N}$ & 78 & 56 & 134 & & \\
\hline & & $\%$ & 47.9 & 54.4 & 50.4 & & \\
\hline \multirow[t]{4}{*}{ Somnolence } & Yes & $\mathrm{N}$ & 51 & 32 & 83 & & \\
\hline & & $\%$ & 31.3 & 31.1 & 31.2 & 0.001 & 0.970 \\
\hline & No & $\mathrm{N}$ & 112 & 71 & 183 & & \\
\hline & & $\%$ & 68.7 & 68.9 & 68.8 & & \\
\hline
\end{tabular}

Notes: Two patients had missing data regarding the use of time (daytime/night). Bold is significant. ${ }^{a} p<0.00 \mathrm{I}$.

Abbreviations: NIV, noninvasive ventilation; ST, spontaneous time; S, spontaneous; IPAP, inspiratory positive airway pressure; EPAP, expiratory positive airway pressure; comp, compliance.

CAT and mMRC scores $(p>0.05)$. The comparison of the groups in terms of these results is given in Table 4.

In the Pearson's correlation analysis, a statistically significant, positive but weak relationship was detected between the compliance of NIV and CAT score and IPAP level. Additionally, a statistically positive and strong (83\%) correlation was detected between the card readout and selfreport in the patients $(n=105)$. The results of the correlation analysis are given in Table 5.

\section{Discussion}

Despite the lack of clear scientific evidence supporting the use of long-term NIV for stable hypercapnic COPD patients, domiciliary NIV is becoming increasingly widespread. ${ }^{3}$ However, to date, standard criteria concerning the time of NIV therapy initiation and treatment compliance in stable COPD remain to be defined. This situation causes deficits for informing and follow-up of the patients by NIV prescribing physicians. ${ }^{7}$ In this study, we detected that $86.7 \%$ of the patients to whom domiciliary NIV was initiated were informed about the ventilator use, and only $38.7 \%$ of the patients returned for follow-up visit by NIV prescribing physicians. Similarly, in a web-survey study performed in ERS-member European countries, only $46 \%$ of the COPD patients to whom domiciliary NIV was initiated are being followed up regularly. ${ }^{7}$ However, careful follow-up in these patients may prevent early deterioration. ${ }^{12}$

Patients must be made to understand that good tolerance and compliance to the ventilator should be ensured to obtain optimal benefit from domiciliary NIV therapy. Our search results revealed no previous "compliance criteria to long-term NIV therapy for COPD patients" in the literature. Therefore, we considered at least 5 hours/d use, which was suggested in many publications in terms of efficacy and compliance, as the cut off value. ${ }^{3,13,14}$ In this setting, compliance rate for NIV therapy was $61 \%$ in our study. In a recent prospective observational study, distribution of the preferred mask types in COPD patients who use domiciliary NIV was explored, 
Table 4 Comparison of the groups in terms of hospitalization and emergency department and ICU admissions within the last year and symptom scoring

\begin{tabular}{|c|c|c|c|c|c|}
\hline Groups & $\begin{array}{l}\text { The number } \\
\text { of patients }\end{array}$ & Mean & SD & $t$ & $p$-value \\
\hline \multicolumn{6}{|c|}{ The number of emergency } \\
\hline \multicolumn{6}{|c|}{ department admission } \\
\hline High compliance & 144 & 4.4 & 5.3 & \multirow{2}{*}{-0.207} & \multirow{2}{*}{0.836} \\
\hline Low compliance & 75 & 4.5 & 4.1 & & \\
\hline \multicolumn{6}{|c|}{ The number of hospitalization } \\
\hline High compliance & 135 & 3.3 & 3.5 & \multirow{2}{*}{1.488} & \multirow{2}{*}{0.138} \\
\hline Low compliance & 85 & 2.7 & 2.0 & & \\
\hline \multicolumn{6}{|c|}{ The number of ICU admission } \\
\hline High compliance & 76 & 1.9 & 1.6 & \multirow{2}{*}{0.755} & \multirow{2}{*}{0.452} \\
\hline Low compliance & 40 & 1.7 & 1.6 & & \\
\hline \multicolumn{6}{|l|}{ CAT score } \\
\hline High compliance & 163 & 25 & 7.6 & \multirow{2}{*}{ I.77। } & \multirow{2}{*}{0.078} \\
\hline Low compliance & 103 & 23 & 8.5 & & \\
\hline \multicolumn{6}{|l|}{ mMRC score } \\
\hline High compliance & 163 & 3.9 & I.I & \multirow{2}{*}{0.428} & \multirow{2}{*}{0.669} \\
\hline Low compliance & 103 & 3.9 & 1.1 & & \\
\hline
\end{tabular}

Notes: High-compliance group ( $n=163)$; low-compliance group $(n=103)$.

Abbreviations: ICU, intensive care unit; CAT, COPD Assessment Test; mMRC, modified Medical Research Council.

and compliance of $\geq 5$ hours was achieved by $70 \%$ of the cohort. ${ }^{15}$ For many patients, domiciliary NIV is a difficultto-tolerate treatment method, and they feel uncomfortable. ${ }^{16}$ The most important components determining the compliance of the patient to NIV include patient's comfort, mask fit and leak, the presence of side effects (ie, nasal congestion, conjunctivitis, sleep interruption), symptoms (dyspnea, morning headache, hypersomnolence), comorbidities, and change in ABG values. ${ }^{17}$ In this study, we detected significantly higher rate of cardiac failure in the high-compliance group than the low-compliance group. To date, the effects of domiciliary NIV on the heart in COPD patients have been rarely investigated. A recent review indicated that use of long-term NIV in chronic hypercapnic respiratory failure contributes to the reduction in the work of breathing and improvement in gas exchange, which in turn may have beneficial effects on the heart. ${ }^{18}$ Additionally, peripheral blood samples were taken from 20 stable hypercarbic COPD patients before and
3 months after the initiation of NIV, and it was detected that reductions in $\mathrm{PaCO}_{2}$ during NIV were associated with decreases in proBNP levels in a recent study. ${ }^{19}$ While the number of dementia patients was very low in our study, the fact that all of these patients were in the low-compliance group may indicate the importance of cognitive function for treatment compliance. We observed higher rate of obesity in the high-compliance group. A recent study included 213 COPD patients (48\% obese) and 47.7 months follow-up. The results showed that survival was better in obese COPD than nonobese COPD, and also compliance to NIV was associated with better prognosis only in obese COPD. ${ }^{20}$ This might be due to the fact that improvements obtained from NIV therapy are more in case of coexistence of obesity and COPD. With regard to side effects, we detected that only conjunctivitis was more frequently seen in the high-compliance group. This may be attributed to longer duration of ventilator exposure and higher IPAP levels in the high-compliance group. We did

Table 5 Assessment of the relationship between the compliance of NIV and IPAP levels, BMI, symptom scores and card readout

\begin{tabular}{|c|c|c|c|c|c|c|}
\hline & & $\begin{array}{l}\text { BMI } \\
\left(\mathrm{kg} / \mathrm{m}^{2}\right)\end{array}$ & $\begin{array}{l}\text { mMRC } \\
\text { score }\end{array}$ & $\begin{array}{l}\text { CAT } \\
\text { score }\end{array}$ & $\begin{array}{l}\text { IPAP } \\
\left(\mathrm{cmH}_{2} \mathrm{O}\right)\end{array}$ & $\begin{array}{l}\text { Compliance of NIV } \\
\text { (card readout) } \\
\text { (hours/d) }\end{array}$ \\
\hline Compliance of NIV (all patients & $r$ & 0.046 & 0.092 & 0.163 & 0.267 & 0.832 \\
\hline$[\mathrm{N}=266]$; card readout or self- & $p$-value & 0.460 & 0.134 & $0.008^{* *}$ & $0.000 * * *$ & $0.000 * * *$ \\
\hline report; hours/d) & $\mathrm{N}$ & 266 & 266 & 266 & 266 & 115 \\
\hline
\end{tabular}

Note: $* * p<0.01, * * * p<0.001$.

Abbreviations: NIV, noninvasive ventilation; IPAP, inspiratory positive airway pressure; BMI, body mass index; mMRC, modified Medical Research Council; CAT, COPD Assessment Test. 
not detect any difference in terms of hypercarbia findings (headache and hypersomnolence) between 2 groups. Some studies exploring the relationship of different types of NIV with treatment compliance in COPD have been published. ${ }^{21,22}$ High IPAP use is proposed as one of the most common reasons for treatment incompatibility. ${ }^{23}$ However, in later randomized controlled trials, high-intensity NPPV has been demonstrated to increase tolerance and compliance compared to the low-intensity NPPV. ${ }^{3,21}$ Similarly, we detected higher IPAP use in the high-compliance group. Furthermore, we also showed a weak but positive correlation between compliance of NIV (hours/d) and IPAP level. The rate of use in ST mode was higher than $\mathrm{S}$ mode in the high-compliance group compared to the low-compliance group in our study. This may be explained by the fact that in ST mode the patient can use higher IPAP, and also ventilation support continues in case of apnea. Sixty-eight percent of the patients had some kind of humidification system; however, we did not detect any difference between the groups in terms of humidifier use. Similarly, in patients with sleep apnea and for whom continuous positive airway pressure treatment was initiated, addition of heat humidification did not make any difference in terms of compliance. ${ }^{24}$ Exacerbation is the most important factor for increased morbidity and mortality in COPD patients. Approximately $10 \%-25 \%$ of the patients who were admitted to the hospital with hypercapnic respiratory failure due to COPD die in hospital. ${ }^{25}$ However, the effects of domiciliary NIV on clinical outcomes of chronic hypercapnic COPD patients have been contradictory in studies and meta-analyses. ${ }^{26-28}$ While in one study, domiciliary NIV significantly decreased hospital admissions, ${ }^{29}$ in another it demonstrated a borderline decrease, ${ }^{30}$ and conversely in another study, it has been demonstrated that hospital admissions are less in patients receiving standard care compared to the patients using NIV. ${ }^{31}$ In a multicenter Italian study, low-intensity NPPV with LTOT and LTOT alone were compared, and no difference was detected in terms of hospital admissions at the end of 2-year follow-up. ${ }^{32}$ On the other hand, in a recent observational study, it has been suggested that decrease may be observed in hospitalization rates and ICU admissions in patients who received high-intensity NPPV. ${ }^{33}$ We did not detect any difference between the high- and the low-compliance groups in terms of hospitalization and emergency department and ICU admissions within the last year. Furthermore, there was no difference between the 2 groups in terms of mMRC and CAT scores in our study. Similarly, in a recent multicenter randomized controlled trial, while a significant improvement in $\mathrm{PaCO}_{2}$ was obtained after 3-month NPPV therapy in stable hypercarbic COPD patients compared to the control group, no difference was detected between the groups in terms of CAT and dyspnea score. ${ }^{14}$ This study has several limitations. First, while the patients were recruited prospectively in a certain period of time, but many patients' ABG and PFTs were recorded retrospectively, if present, in their previous follow-ups. Second, we could only get card readout data in 115 patients, but also we detected a statistically high concordance between these patients' own statement and card readout data. Third, the number of hospital admissions within the last year were recorded retrospectively. Finally, this study was designed as a real-life trial and we included COPD patients with accompanying OSA or obesity. However, we thought that this was not a substantial limitation, and also we had the opportunity to investigate the effect of coexistence of these situations with COPD on the domiciliary NIV compliance.

\section{Conclusion}

We believe that the patient and ventilator factors which may be related to domiciliary NIV treatment compliance were comprehensively evaluated in our study, which has revealed very substantial results. Accurate determination of the patients who may have better compliance to NIV therapy will enable better patient selection and also help in defining optimal ventilator type and settings suitable for the patient so as to improve their treatment compliance. New studies on this topic are needed to increase long-term treatment compliance and response.

\section{Acknowledgments}

COHOV Study Group: Firat Uygur, Fatma Merve Tepetam, Sinem Güngör, Sibel Arınç, Ülkü Aka Aktürk, Ünal Şahin, Elif Tanrıverdi, Serap Argun Barış, Talat Kılıç, Emine Argüder, Dildar Duman, Aylin Özsancak Uğurlu, Ömer Tamer Doğan, Didem Görgün Hattatoğlu, Tuğba Önyılmaz, Ayşe Havan, Ümran Toru, Ebru Çakır Edis, Ersin Günay, Recep Işık, Emel Bulcun, Sibel Günay, Mürşide Demirhan Uzun, Bülent Altınsoy, Müge Özdemir, Özgecan Karahan, Pınar Atagün Güney, Dilek Ernam, Demet Turan, Aziz Gümüş, Mehmet Baran Balcan, Serdar Berk, Birsen Pınar Yildiz. The authors would like to thank The Association of Lung Health and Intensive Care for financial support in the publication of the article. The authors also gratefully acknowledge the support of Turkish Respiratory Society for help with the statistical analysis of this study.

\section{Disclosure}

The authors report no conflicts of interest in this work. 


\section{References}

1. Lozano R, Naghavi M, Foreman K, et al. Global and regional mortality from 235 causes of death for 20 age groups in 1990 and 2010: a systematic analysis for the Global Burden of Disease Study 2010. Lancet. 2012;380(9859):2095-2128.

2. Foucher P, Baudouin N, Merati M, et al. Relative survival analysis of 252 patients with COPD receiving long-term oxygen therapy. Chest. 1998;113(6):1580-1587.

3. Struik FM, Lacasse Y, Goldstein RS, Kerstjens HA, Wijkstra PJ. Nocturnal noninvasive positive pressure ventilation in stable COPD: a systematic review and individual patient data meta-analysis. Respir Med. 2014;108(2):329-337.

4. Vestbo J, Hurd SS, Agustí AG, et al. Global strategy for the diagnosis, management, and prevention of chronic obstructive pulmonary disease: GOLD executive summary. Am J Respir Crit Care Med. 2013;187(4): 347-365.

5. Elliott MW, Mulvey DA, Moxham J, Green M, Branthwaite MA. Domiciliary nocturnal nasal intermittent positive pressure ventilation in COPD: mechanisms underlying changes in arterial blood gas tensions. Eur Respir J. 1991;4(9):1044-1052.

6. Duiverman ML, Wempe JB, Bladder G, et al. Two-year home-based nocturnal noninvasive ventilation added to rehabilitation in chronic obstructive pulmonary disease patients: a randomized controlled trial. Respir Res. 2011;12:112.

7. Crimi C, Noto A, Princi P, et al. Domiciliary non-invasive ventilation in COPD: an international survey of indications and practices. COPD. 2016;13(4):483-490.

8. Consensus conference. Clinical indications for non-invasive positive pressure ventilation in chronic respiratory failure due to restrictive lung disease, COPD and nocturnal hypoventilation - a consensus conference report. Chest. 1999;116(2):521-534.

9. Charlson ME, Pompei P, Ales KL, MacKenzie CR. A new method of classifying prognostic comorbidity in longitudinal studies: development and validation. J Chronic Dis. 1987;40(5):373-383.

10. Bestall JC, Paul EA, Garrod R, Garnham R, Jones PW, Wedzicha JA. Usefulness of the Medical Research Council (MRC) dyspnoea scale as a measure of disability in patients with chronic obstructive pulmonary disease. Thorax. 1999;54(7):581-586.

11. Jones PW, Harding G, Berry P, Wiklund I, Chen WH, Kline Leidy N. Development and first validation of the COPD assessment test. Eur Respir J. 2009;34(3):648-654.

12. Funk GC, Breyer MK, Burghuber OC, et al. Long-term non-invasive ventilation in COPD after acute-on-chronic respiratory failure. Respir Med. 2011;105(3):427-434.

13. Köhnlein T, Windisch W, Köhler D, et al. Non-invasive positive pressure ventilation for the treatment of severe stable chronic obstructive pulmonary disease: a prospective, multicentre, randomised, controlled clinical trial. Lancet Respir Med. 2014;2(9):698-705.

14. Zhou L, Li X, Guan L, et al. Home noninvasive positive pressure ventilation with built-in software in stable hypercapnic COPD: a shortterm prospective, multicenter, randomized, controlled trial. Int J Chron Obstruct Pulmon Dis. 2017;12:1279-1286.

15. Callegari J, Magnet FS, Taubner S, et al. Interfaces and ventilator settings for long-term noninvasive ventilation in COPD patients. Int $J$ Chron Obstruct Pulmon Dis. 2017;12:1883-1889.

16. Wild MR, Engleman HM, Douglas NJ, Espie CA. Can psychological factors help us to determine adherence to CPAP? A prospective study. Eur Respir J. 2004;24(3):461-465.

17. Díaz-Lobato S, Alises SM, Rodríguez EP. Current status of noninvasive ventilation in stable COPD patients. Int J Chron Obstruct Pulmon Dis. 2006;1(2):129-135.
18. Duiverman ML, Arellano-Maric MP, Windisch W. Long-term noninvasive ventilation in patients with chronic hypercapnic respiratory failure: assisting the diaphragm, but threatening the heart? Curr Opin Pulm Med. 2016;22(2):130-137.

19. Dreher M, Schulte L, Müller T, Ekkernkamp E, Zirlik A. Influence of effective noninvasive positive pressure ventilation on inflammatory and cardiovascular biomarkers in stable hypercapnic COPD patients. Respir Med. 2015;109(10):1300-1304.

20. Borel JC, Pepin JL, Pison C, et al. Long-term adherence with noninvasive ventilation improves prognosis in obese COPD patients. Respirology. 2014;19(6):857-865.

21. Dreher M, Storre JH, Schmoor C, Windisch W. High-intensity versus low-intensity non-invasive ventilation in patients with stable hypercapnic COPD: a randomised crossover trial. Thorax. 2010;65(4):303-308.

22. Oscroft NS, Ali M, Gulati A, et al. A randomised crossover trial comparing volume assured and pressure preset noninvasive ventilation in stable hypercapnic COPD. COPD. 2010;7(6):398-403.

23. Aloia MS, Stanchina M, Arnedt JT, Malhotra A, Millman RP. Treatment adherence and outcomes in flexible vs standard continuous positive airway pressure therapy. Chest. 2005;127(6):2085-2093.

24. Mador MJ, Krauza M, Pervez A, Pierce D, Braun M. Effect of heated humidification on compliance and quality of life in patients with sleep apnea using nasal continuous positive airway pressure. Chest. 2005; 128(4):2151-2158.

25. Connors AF Jr, Dawson NV, Thomas C, et al. Outcomes following acute exacerbation of severe chronic obstructive lung disease. The SUPPORT investigators (Study to Understand Prognoses and Preferences for Outcomes and Risks of Treatments). Am J Respir Crit Care Med. 1996;154(4 Pt 1):959-967.

26. Dretzke J, Moore D, Dave C, et al. The effect of domiciliary noninvasive ventilation on clinical outcomes in stable and recently hospitalized patients with COPD: a systematic review and meta-analysis. Int J Chron Obstruct Pulmon Dis. 2016;11:2269-2286.

27. Kolodziej MA, Jensen L, Rowe B, Sin D. Systematic review of noninvasive positive pressure ventilation in severe stable COPD. Eur Respir J. 2007;30(2):293-306.

28. Wijkstra PJ, Lacasse Y, Guyatt GH, et al. A meta-analysis of nocturnal noninvasive positive pressure ventilation in patients with stable COPD. Chest. 2003;124(1):337-343.

29. Xiang PC, Zhang X, Yang JN, et al. [The efficacy and safety of long term home noninvasive positive pressure ventilation in patients with stable severe chronic obstructive pulmonary disease]. Zhonghua Jie He He Hu Xi Za Zhi. 2007;30(10):746-750. Chinese.

30. Cheung AP, Chan VL, Liong JT, et al. A pilot trial of non-invasive home ventilation after acidotic respiratory failure in chronic obstructive pulmonary disease. Int J Tuberc Lung Dis. 2010;14(5):642-649.

31. Struik FM, Sprooten RT, Kerstjens HA, et al. Nocturnal non-invasive ventilation in COPD patients with prolonged hypercapnia after ventilatory support for acute respiratory failure: a randomised, controlled, parallel-group study. Thorax. 2014;69(9):826-834.

32. Clini E, Sturani C, Rossi A, et al; Rehabilitation and Chronic Care Study Group; Italian Association of Hospital Pulmonologists (AIPO). The Italian multicentre study on noninvasive ventilation in chronic obstructive pulmonary disease patients. Eur Respir J. 2002;20(3):529-538.

33. Windisch W, Haenel M, Storre JH, Dreher M. High-intensity noninvasive positive pressure ventilation for stable hypercapnic COPD Int J Med Sci. 2009;6(2):72-76. 


\section{Publish your work in this journal}

The International Journal of COPD is an international, peer-reviewed journal of therapeutics and pharmacology focusing on concise rapid reporting of clinical studies and reviews in COPD. Special focus is given to the pathophysiological processes underlying the disease, intervention programs, patient focused education, and self management protocols.

This journal is indexed on PubMed Central, MedLine and CAS. The manuscript management system is completely online and includes a very quick and fair peer-review system, which is all easy to use. Visit http://www.dovepress.com/testimonials.php to read real quotes from published authors.

Submit your manuscript here: http://www.dovepress.com/international-journal-of-chronic-obstructive-pulmonary-disease-journal 